niet-betaalde arbeid, en aan het betalen van maatschappelijk nuttige activiteiten. Het colloquium van 1988 dat hiervan een synthese moest maken, trok nog vele geïnteresseerden aan maar was tegelijk de zwanenzang van Polekar. Een voor een haakten de oude voortrekkers af tot er nog maar een kleine kern overbleef. Het was het einde van wat ooit de leidende denktank van de Vlaamse linkerzijde werd genoemd.

Het archief van Polekar werd eind 2005 door Frank Moulaert aan Amsab-ISG overgedragen, dankzij de goede zorgen van Natan Hertogen die het materiaal eerst gebruikt had voor zijn licentiaatsverhandeling over Polekar. Moulaert speelde een centrale rol in Polekar: hij zat in de stuurgroep en verzorgde de contacten met $D e$ Nieuwe Maand. Het is waarschijnlijk dat het archief van de verschillende werkgroepen nog verspreid zit bij de leden van de werkgroepen. Maar de 5 dozen materiaal en de 24 beschrijvingen zijn in alle geval al ee uitstekende bron voor de studie van deze bijzonder invloedrijke werkgroep.

(1) Deze inleiding is grotendeels gebaseerd op de licentiaatsverhandeling van N. HERTOGEN, Polekar (Werkgroep politieke ekonomie en arbeid). Ideeënvijver voor links Vlaanderen 1978-1989. Een socio-politiek parcours naar centerstage, UGent, licen-

(2) Amsab-ISG, Archief Polekar, Wat is Polekar?

Aortingsteks, 1985, nr. 375, 14

\section{Het inventariseren van \\ mondelinge historische bronnen in Amsab-ISG}

\author{
A Bart De Nil, Amsab-ISG
}

Over mondelinge geschiedenis is er de laatste jaren al heel wat geschreven en gezegd. Zij het dan vooral over de productie en het valoriseren van mondelinge historische bronnen voor allerlei erfgoedprojecten. Over de uiteindelijke bewaring en ontsluiting van deze bronnen is minder geweten. Uit het eindverslag van het onderzoeksproject Van horen zeggen: mondelinge, historische bronnen bewaren en ontsluiten uit 2004 blijkt dat het hiermee niet zo goed is gesteld. In dit verslag, dat werd opgesteld op basis van een bevraging binnen de sector en een onderzoek van enkele zogenaamde 'best cases', kwam Roel Vande Winkel tot de vaststelling dat: "De bewaring/ontsluiting van in het verleden geproduceerde/verworven bronnencollecties doorgaans problematisch is. De toegang tot vele interviews wordt inhoudelijk belemmerd (vb. door een gebrek aan catalogisering/ontsluiting of het ontbreken van randdocumenten) evenals de materiële toegankelijkheid ( $v$ b. door de fysieke degeneratie van geluids- en beelddragers). Vaak zijn onvoldoende tijd, middelen en expertise voorhanden om deze problemen het hoofd te bieden." Redenen genoeg om bij de beleidsaanbevelingen te pleiten voor de oprichting van een expertisecentrum voor mondelinge geschiedenis en voor de ontwikkeling van een gestandaardiseerde catalografiemodule. Maar toch wijst Vande Winkel erop dat elk van de geconsulteerde instellingen op haa terrein een voorbeeldfunctie vervult. Ove Amsab-ISG schrijft hij: "Het Amsab-Instituu voor Sociale Geschiedenis ontwikkelde een gesofisticeerd programma om mondelinge, historische bronnen te ontsluiten." Een vleiende opmerking, alhoewel ik hieraan eerlijkheidshalve moet toevoegen dat we nog maar aan het begin staan van het procesmatig ontsluiten van mondelinge bronnen; want zoals het archiveren van een papieren archief veel meer is dan het vullen van archiefdozen, vergt de ontsluiting van historische mondelinge bronnen het nodige vakmanschap en technische infrastructuur.

Het gesofisticeerd programma waarnaa hij verwijst is de Accesdatabank waarin momenteel 309 interviews staan beschreven. Het merendeel is afkomstig van de vakgroep Nieuwste Tijden van de Universiteit Gent die zich binnen de academisch wereld de pionier in het gebruik van de mondelinge geschiedenis voor historisc onderzoek mag noemen. Geregeld ze deze vakgroep grote interviewprojecten op in het kader van studentenoefeninge en hij werkt nauw samen met de erfgoedsector om de mondelinge geschiedenis te populariseren. Een voorbeeld hiervan is de uitgave, samen met het Vlaams Centrun voor Volkscultuur, van de dvd Van Hore Zeggen: Mondelinge Geschiedenis in de praktijk. De interviews die pasten in de collectie of werden gemaakt in samenwerking met Amsab-ISG werden door de vakgroep aan de instelling geschonken.

Hieronder volgt een beschrijving van de verschillende collecties in de databank opgenomen; voor de databankstructuur diende de webcatalogus van de National Sound Archive van de British Library als voorbeeld. $\mathrm{Na}$ de beschrijving kregen de paradocumenten (transscriptie van het interview, uitgeschreven onderzoeksproject, identificatiefiches van de respondenten enz.), geschoond en opgeborgen in zuurvrije dozen, een plaats in het departement Archief, de dragers (audiocassettes) werden overgebracht naar het departement Beeld $\&$ Geluid. Deze databank is een bescheiden startpunt, met de beschrijving van de interviews werd een eerste stap gezet in het proces van bewaring en ontsluiting van mondelinge historische bronnen. In een volgende fase moeten de analoge dragers (audiocassettes) omgezet worden naar een digitaal formaat. We willen hierbij echter niet over één nacht ijs gaan. Het heeft immers geen zin om een lijst van digitale audiobestanden te presenteren als men die niet kan koppelen aan een geavanceerde beschrijvingsmodule die met een zoekmodule via het internet raadpleegbaar is. Voor de realisatie van een dergelijk informaticaplatform zijn sectoroverschrijdende samenwerkingsverbanden nodig. Daartoe sloegen, gecoördineerd door de vakgroep Nieuwste Geschiedenis van de Universiteit Gent, de tien erfgoedcellen, de vier archiefinstellingen (Amsab-ISG, ADVN, KADOC, Stadsarchief Antwerpen), het VRT-Geluidsarchief Radio, VolkskundeVlaanderen en het Vlaams Centrum voor Volkscultuur de handen in elkaar. Met als resultaat dat in het najaar kan worden ge- 
start met een haalbaarheidsstudie van een innovatieve applicatie voor de ontsluiting van mondelinge bronnen in Vlaanderen: project Van Horen Zeggen fase III. Dit moet een rapport opleveren waarin "de mogelijkheid wordt nagegaan om in Vlaanderen een applicatie of systeem te ontwikkelen dat inspeelt op (een aantal van) de diverse behoeften op het vlak van productie, ontsluiting, opslag, bewaring en valorisering van (digitale) mondelinge bronnen." Met andere woorden, er wordt een voorzet gegeven om een informaticasysteem te ontwikkelen om mondelinge historische bronnen te archiveren en beschikbaar te stellen voor het publiek. Hopelijk pikt het beleid volgend jaar deze voorzet op zodat binnen afzienbare tijd onze collectie mondelinge historische bronnen online raadpleegbaar is

Interviewproject Arbeiders-studenten In de eerste helft van de jaren 1980 deed toenmalig RUG-hoogleraar Herman Balthazar samen met zijn studenten op basis van mondelinge bronnen onderzoek naar de arbeiders- en studentenbeweging voor en na 1968. De interviews werden in het academiejaar 1981-1982 afgenomen door de studenten van de tweede licentie, van de 68 zijn er 31 teruggevonden; enkel de basisfiches met integrale transscriptie zonder de opnames.

Interviewproject Rood of geen brood Deze interviews werden afgenomen in het kader van het project Rood of geen brood, een practicum in het vak methodologie van de Nieuwste Tijden partim mondelinge geschiedenis in de tweede kandidatuur geschiedenis, academiejaar 1998-1999 docent: prof. dr. Bruno De Wever). De stuenten interviewden leden en werknemers van de Gentse socialistische verbruikscoöperatie over hun belevenissen binnen de socialistische zuil.

\section{Interviewproject Over de bloemetjes} en de bitjes

Een practicum in het vak methodologie van de Nieuwste Tijden partim mondelinge geschiedenis in de tweede kandidatuur reschiedenis, academiejaren 1996-1997 en 1997-1998 (docent: prof. dr. Bruno De Wever).

Aan de hand van een aantal vragen werd nagegaan hoe de geïnterviewde seksueel voorgelicht werd (wanneer, waar, hoe, door wie enz.). Ook werd gevraagd naar zijn mening over anticonceptie en voorbehoedmiddelen. De geïnterviewden kwamen allemaal min of meer uit een socialistisch milieu.

De interviews werden verwerkt in een bijdrage in de publicatie Begeerte heeft ons aangeraakt. Socialisten, sekse en seksualiteit, nummer 16 in de reeks Bijdragen Museum van Vlaamse Sociale Strijd uitgegeven door AMSAB in 1999 in opdracht van de provincie Oost-Vlaanderen.

\section{Interviewproject Staking van 1981} op de Boelwerf

De interviews werden afgenomen in het kader van de eindverhandeling van Ann Vanden Wyngaerd De staking van 1981 op e Boelwerf: het roer uit handen?: een micronderzoek van een collectieve actie vanuit de veldtheorie van P. Bourdieu (UGent, 1994). We hebben enkel de opnames van de interviews afgenomen door Vanden Wyngaerd (nrs.
14, 16 t.e.m. 24). Van de andere interviews, afgenomen door collega-studenten (va Vanden Wyngaard) hebben we enkel de paradocumenten. Er staat een embargo op het gebruik van de interviews door derden, gespecificeerd in het depotcontract.

\section{Het archief van Michie}

Bart De Nil, Amsab-ISG

Op 5 april 2006 overleed op 61-jarige leeftijd na een slepende ziekte de Brusselse politicus Michiel Vandenbussche. Een man die zowel binnen en buiten zijn partij bekend stond als een rechtvaardig, uitermate sociaal geëngageerd en beminnelijk man.

Michiel Vandenbussche werd geboren in Roeselare op 9 januari 1945. Hij studeerd politieke en sociale wetenschappen aan de Leuvense Universiteit. Tijdens zijn studies engageerde hij zich in de studentenbe weging. Vandenbussche ging in 1970 als sociaal-cultureel werker in Brussel wonen. Hij geraakte er betrokken bij het Vlaamse sociaal-culturele leven en zette zich onde meer actief in voor de congressen van de Brusselse Vlamingen. Zijn eerste stappen in de politiek zette hij als kabinetsadviseu en later als kabinetschef bij staatssecretaris Lydia De Pauw-Deveen. Vandenbussche was vooral politiek actief in Etterbeek waar hij in 1982 als Vlaamse socialist werd verkozen tot gemeenteraadslid op de Lijst van de Burgemeester. Vanaf 1989 was hij schepen in Etterbeek. In Etterbeek zette Vandenbussche zich in voor het Vlaamse culturele leven en hij richtte er de Louis Paul Boon Kring op. Binnen de Socialistische Partij was Vandenbussche een pleitbezorger voor de rechten van de Brusselse Vlamingen en ageerde hij fel tegen de discriminatie van allochtonen. Hij was onder meer ook een tijdlang voorzitter van CSC-vormingswerk. Vandenbussche was sinds 1989 ook lid van het Brussels en Vlaams Parlement en van de raad Vlaamse Gemeenschapscommissie, een functie waaruit hij in 1999 vrijwillig ontslag nam om plaats te ruimen voor Anne Van Asbroeck. Ter gelegenheid hiervan verscheen er een Liber Amicorum met onder meer bijdragen van Geert Van Istendael, Johan Verminnen, Els Witte, Benno Barnard.

Het archief van Vandenbussche werd geïnventariseerd en geeft een goed beeld van het engagement van een pluralistische Etterbekenaar die een belangrijke rol heeft gespeeld in de strijd tegen de discriminatie van minderheden in Brussel. Het archief dat hoofdzakelijk bestaat uit dossiers, nota's en briefwisseling beslaat 49 nummers, opgeborgen in 3 dozen. Het is toegankelijk mits toelating van de dienstdoende archivaris. 